\title{
Comprehensive report on Materials for Gas Turbine Engine Components
}

\author{
Anushraj B, Winowlin Jappes J T, Adam Khan M, Dillibabu V and Brintha N C
}

\begin{abstract}
In the past three decades, it is very challenging for the researchers to design and development a best gas turbine engine component. Engine component has to face different operating conditions at different working environments. Nickel based superalloys are the best material to design turbine components. Inconel 718, Inconel 617, Hastelloy, Monel and Udimet are the common material used for turbine components. Directional solidification is one of the conventional casting routes followed to develop turbine blades. It is also reported that the raw materials are heat treated / age hardened to enrich the desired properties of the material implementation. Accordingly they are highly susceptible to mechanical and thermal stresses while operating. The hot section of the turbine components will experience repeated thermal stress. The halides in the combination of sulfur, chlorides and vanadate are deposited as molten salt on the surface of the turbine blade. On prolonged exposure the surface of the turbine blade starts to peel as an oxide scale. Microscopic images are the supportive results to compare the surface morphology after complete oxidation / corrosion studies. The spectroscopic results are useful to identify the elemental analysis over oxides formed. The predominant oxides observed are $\mathrm{NiO}, \mathrm{Cr} 2 \mathrm{O3}$, $\mathrm{Fe} 2 \mathrm{O3}$ and $\mathrm{NiCr} 2 \mathrm{O} 4$. These oxides are vulnerable on prolonged exposure and according to $P B$ ratio the passivation are very less. In recent research, the invention on nickel based superalloys turbine blades produced through other advanced manufacturing process is also compared. A summary was made through comparing the conventional material and advanced materials performance of turbine blade material for high temperature performance.
\end{abstract}

Keywords: nickel, corrosion, oxide, SEM, EDS, XRD

\section{INTRODUCTION}

$\mathrm{G}_{\text {as turbine engine component has to face severe }}$ working temperature [1]. Nickel based superalloys of different grade are used for gas turbine engine components [2]. In general the nickel based superalloys are stable at elevated temperature for oxidation/ corrosion for certain duration.

Revised Manuscript Received on December 30, 2019.

* Correspondence Author

Anushraj B, Centre for Surface Engineering, Department of Mechanical Engineering, Kalasalingam Academy of Research \& Education, Virudhunagar, Tamilnadu, India Email: anushrajb@gmail.com

Winowlin Jappes J T, Centre for Surface Engineering, Department of Mechanical Engineering, Kalasalingam Academy of Research \& Education, Virudhunagar, Tamilnadu, India Email: winowlin@klu.ac.in

Adam Khan $\mathbf{M}^{*}$, Centre for Surface Engineering, Department of Mechanical Engineering, Kalasalingam Academy of Research \& Education, Virudhunagar, Tamilnadu, India, Email: adamkhanm@gmail.com

Dillibabu V, Scientist, Small Turbo Fan Section, Gas Turbine Research Establishment (GTRE), DRDO, Bangalore, India. Email: dilli.drdo@gmail.com

Brintha N C, Department of Computer Science and Engineering, Kalasalingam Academy of Research and Education, Virudhunagar, Tamilnadu, India. Email: brinthachris2k@gmail.com
Due to this characteristic the metal is used for high temperature application [4].Basically superalloys are FCC in structure [5]. The applications of superalloys with their properties of different grade are explained by Matthew \& Stephen [6] and George [7].

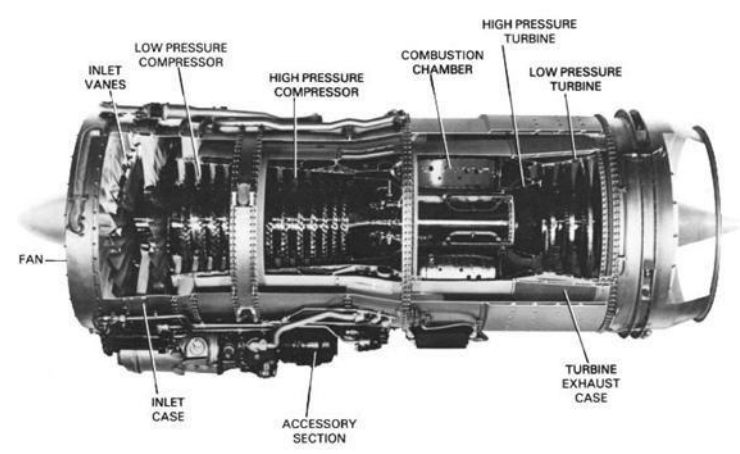

Fig 1: Cross of Section of Light Combat Aircraft - Gas Turbine Engine. [3]

\section{ADDITIVE MANUFACTURING MATERIALS}

Recently, research on additive manufacturing process has been adopted to manufacture gas turbine engine components. Juillet et al [8] made an attempt to develop IN718 a nickel based superalloy. Investigations are made to compare the forged component and additive manufactured component with reference to the formation of $\mathrm{Cr}_{2} \mathrm{O}_{3}$ scale. Moussaoui et al [9] investigated on selective laser melting (SLM) of IN718 to study the effect of porosity effect of the alloy. The micro hardness of the SLM manufactured component is increased with the effect of heat treatment. Chongliang Zhong et al [10] Compares IN718 and IN625 superalloys are manufactured by additive manufacturing the deposition rate of laser metal deposition. The material deposition is good for IN 718 when compared to IN625. Bonny Onuike et al [11] compares thermal properties of IN 718 and bimetal of copper and IN 718 manufactured by additive manufacturing. The thermal diffusivity and conductivity is increased for pure IN718. Mario Valdez et al [12] developed IN 718 superalloy through laser based additive manufacturing. The complex shapes are easily produced in short period of time. In powder bed fusion method the process parameter are highly influencing the component microstructure. By reducing scan speed and hatch distance and increase the laser power increase the density of the material. The dense additively manufactured component has less porosity. 


\section{Comprehensive report on Materials for Gas Turbine Engine Components}

The dense additively manufactured component has less porosity. It was found that density of material is good then it gives good tensile strength and impact strength.

Built direction of laser based AM are shown in figure 2. It infers the microstructure of the samples at different direction and orientation [13]. Lin Zhu et al [14] reported the laser based AM process and its properties for IN718. The laser solid forming treatment with solution treated samples of different age conditions are compared. It was reported that HA samples gives good strength and microhardness at the same samples manufactured at $1350 \mathrm{~W}$ laser power gives fine grain. Xing Li et al [15] made an attempt to study the heat treatment of DSLM produced samples. It has reported that solution plus ageing sample obtained higher volume of fraction which improves the hardness of the material. Tiana et .al [16] comparison of annealed and age hardened \& two step aged hardened of laser powder deposition alloy was investigated. The author reported that in annealed and age hardened alloy gives good tensile strength at both ambient and elevated temperatures. The $\mathrm{Li}$ et al [17] explains the importance of the heat treatment of SLM manufactured components. The material manufactured by SLM cannot be used as it manufactured since the material will have columnar grain, porosity and undesired properties. The material should undergo heat treatment process to get desired grain size, reduces porosity, improve the density and tensile strength.

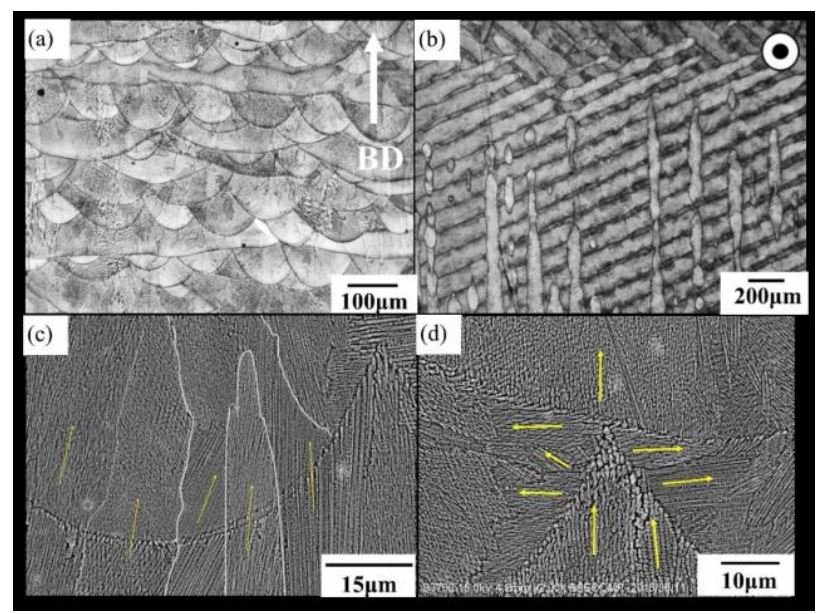

Fig. 2: MPB microstructures of the as-built specimen: (a) side view and (b) top view [13].

Konecna et al [18] compared the SLM manufactured over conventional by manufactured IN718 alloy to report the crack growth of the alloy on mechanical condition. Probstle et al [19] treated SLM alloy have high creep strength when compared to wrought material. Kuo et al [20] revealed that the direct aged SLM component of IN718 have improved creep strength when compared to wrought material. Strano et al [21] claimed that surface roughness of SLM component is affected by the parameter like laser power, hatch distance, scanning speed, part geometry and scanning strategy.

\section{CORROSION IN GAS TURBINE ENGINE}

Gurrappa et al [22] compares the single crystal nickel based alloy with IN 792 and CMSX 4 superalloys. It was reported that single crystal nickel alloy founds to be the best to resist sulfur and chlorine reactions during combustion of the engine at elevated temperature. Gonzalez et al [23] performed corrosion studies on heat resistant alloys with two different molten salts. Corrosion starts from the chromium depletion on the external surface in the form of oxides. The internal corrosion may happen due to the form of sulfate. T.S.Sidhu et al [24] made an attempt on molten salt corrosion of nickel coated alloy at $900^{\circ} \mathrm{C}$. During combustion $\mathrm{V}_{2} \mathrm{O}_{5}$ and $\mathrm{Na}_{2} \mathrm{So}_{4}$ are deposit on the surface of the surface of the material. Chromium and silicon oxides offer better hot corrosion due to their slow growth and act as barrier for ionic implantation.

Saber et al [25] made a study on high temperature cyclic oxidation on nickel alloys. The investigation is made at different operating temperatures to report change in mass during exposure and its kinetics. The $\mathrm{Cr}_{2} \mathrm{O}_{3}, \mathrm{NiO}$ and $\mathrm{NiCr}_{2} \mathrm{O}_{4}$ are protective layer developed on prolonged exposure of the alloy. It is due to the internal and external oxide elements migration. The thickness of oxide layer found increasing with time and operating condition.
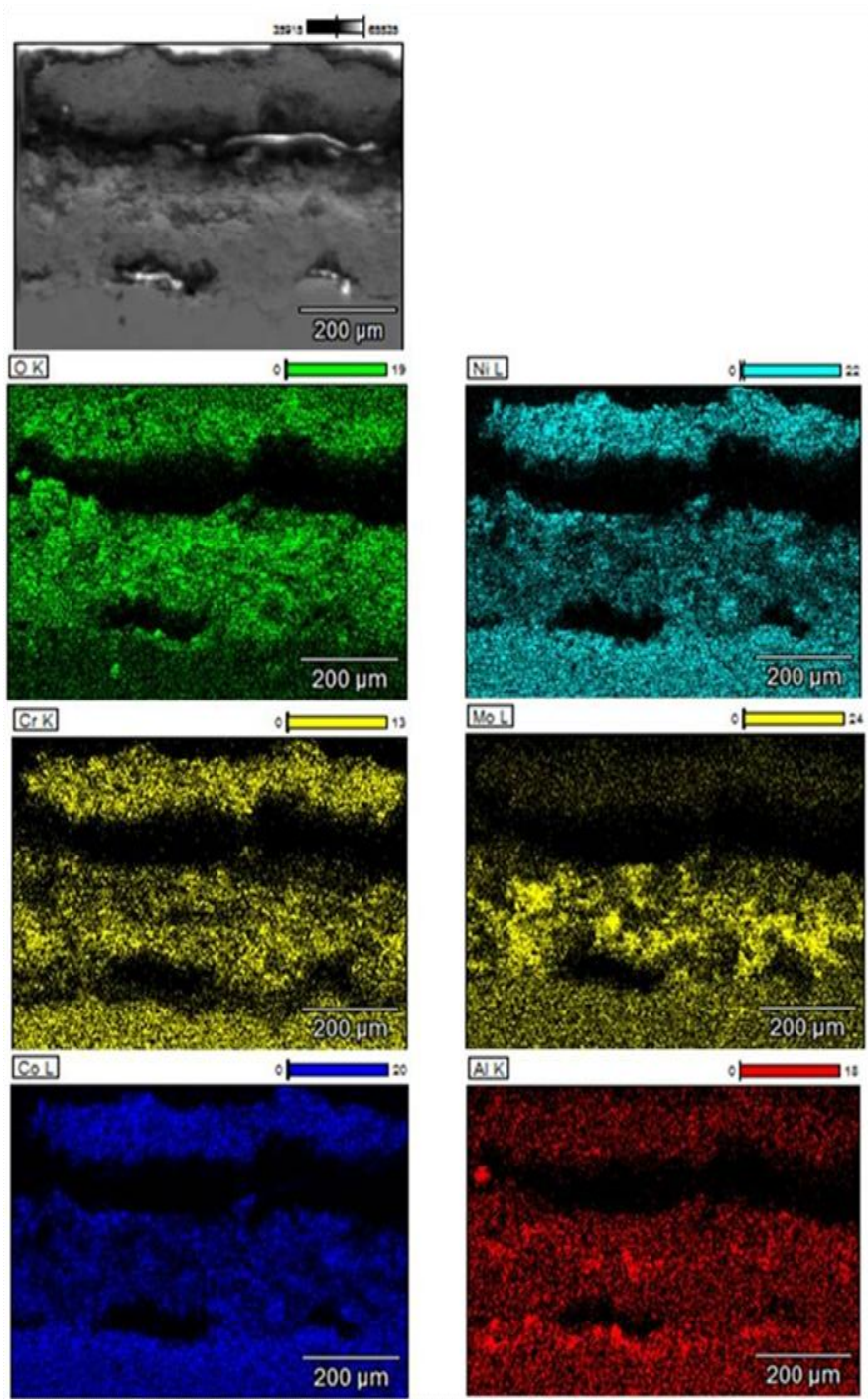

Fig 3: Electron image and $X$ - ray scan image mapping of $\mathrm{NiCr}-\mathrm{Cr} 2 \mathrm{O3}$ coated sample exposed at $1000^{\circ} \mathrm{C}$. [2] 


\section{TENSILE STRENGTH IN GAS TURBINE MATERIAL}

Demetriou et al [28] investigated age hardening alloy and reported how the grain growth of different prime phase is attained. At the same age hardening in nickel alloy and its strengthen are compared. It improves the tensile strength of the nickel alloy. Noguchi et al [29] reported that the cyclic fatigue of superalloy is not only affected by age hardened materials. There is slight difference in the age hardened and non aged hardened materials. Similarly the tensile strength of non-age hardened material has good strength when compared to age hardened material. And there is slight difference in $1000 \mathrm{hr}$ age hardened and $5000 \mathrm{hr}$ age hardened for $700^{\circ} \mathrm{C}$ materials. Enxiang Pu et al [30] investigated mechanical and metallurgical properties of solution treated nickel based alloy. The report on grain growth and grain size are observed that the solutionizing temperature will increase the grain growth and reduced on exposure. The tensile ductility and work hardening component (n) was increased and tensile strength and strain hardening rate is reduced while the increasing grain growth of the material. Y.C. Lin et al [31] investigated on work hardening of superalloy can be achieved by solutionizing cooling process. With raise in temperature the size of $\gamma^{\prime \prime}$ phase rapidly decreases. Li-ming TAN et al [32] reported that the increasing the chromium, cobalt, tungsten and Molybdenum content the tensile strength is improved. Demetriou et al [28] investigated age hardening alloy and reported how the grain growth of different prime phase is attained. At the same age hardening in nickel alloy and its strengthen are compared. It improves the tensile strength of the nickel alloy. Noguchi et al [29] reported that the cyclic fatigue of superalloy is not only affected by age hardened materials. There is slight difference in the age hardened and non aged hardened materials. Similarly the tensile strength of non-age hardened material has good strength when compared to age hardened material. And there is slight difference in $1000 \mathrm{hr}$ age hardened and $5000 \mathrm{hr}$ age hardened for $700^{\circ} \mathrm{C}$ materials. Enxiang Pu et al [30] investigated mechanical and metallurgical properties of solution treated nickel based alloy. The report on grain growth and grain size are observed that the solutionizing temperature will increase the grain growth and reduced on exposure. The tensile ductility and work hardening component (n) was increased and tensile strength and strain hardening rate is reduced while the increasing grain growth of the material. Y.C. Lin et al [31] investigated on work hardening of superalloy can be achieved by solutionizing cooling process. With raise in temperature the size of $\gamma^{\prime \prime}$ phase rapidly decreases. Li-ming TAN et al [32] reported that the increasing the chromium, cobalt, tungsten and Molybdenum content the tensile strength is improved.

\section{SUMMARY}

- Nickel based superalloys are used in gas turbine application. They are single crystal austenitic structure with good mechanical properties has supported to high temperature applications. However, they are prone to corrode on prolonged exposure at different operating conditions such as molten salt, temperature and time.

- To increase the stability, superalloys are heat treated / age hardened. At majority samples are coated with thermal barrier coatings to resist corrosion and oxidation. During high temperature exposure, the scale formed with protective metallic / intermetallic oxides are also extending the surface from cyclic corrosion.

- Additive manufacturing is a recent technique adopted to produce turbine engine components. Inherently, the mechanical properties are superior when compared commercial alloys.

Therefore, it is confirmed that the additive manufacturing process can be adopted to develop the turbine component. At the same the heat treatment can be proposed to enrich the mechanical and metallurgical quality of the sample.

\section{REFERENCES}

1. Adam Khan M, Sundarrajan S, Natarajan S, Parameswaran P and Mohandas E "Oxidation \& hot corrosion behavior of Nickel based superalloy for Gas Turbine Applications". Materials and Manufacturing Processes, (2014), 29, $1-8$.

2. Adam Khan $\mathrm{M}$, Sundarrajan $\mathrm{S}$ and Natarajan $\mathrm{S}$ "Cyclic hot corrosion behaviour of Inconel 617 with $\mathrm{Na}_{2} \mathrm{SO}_{4} / \mathrm{NaCl} / \mathrm{V}_{2} \mathrm{O}_{5}$ molten salt environment at $900^{\circ}$ and $1000^{\circ} \mathrm{C}$ ", High Temperature Materials and Processes (Accepted - 2014) [DOI: 10.1515/htmp-2014-0054, June 2014].

3. Courtesy of United Technologies Corporation, Pratt \&Whitney Aircraft (JT8D turbofan engine)

4. Adam Khan M, Sundarrajan S and Natarajan S "Influence of Plasma coatings on Inconel617 for gas turbine applications", Surface Engineering, (2014) 30 (9), 656 - 661.

5. Joseph R. Davis Nickel, Cobalt, and Their Alloys, ASM International, Materials Park, Ohio, 2000.

6. George Y. Lai High-Temperature Corrosion and Materials Applications, ASM International, Materials Park, Ohio, USA, 2007.

7. Matthew J. Donachie and Stephen J. Donachie SUPERALLOYS: A Technical Guide, Second Edition, ASTM International, Materials Park, Ohio, USA, 2002

8. C. Juillet, A. Oudriss, J. Balmain, X. Feaugas, F.PedrazaCharacterization and oxidation resistance of additive manufactured and forged IN718 Ni-based superalloys, Corrosion Science (2018), https://doi.org/10.1016/j.corsci.2018.07.032

9. K. Moussaoui, W. Rubio, M. Mousseigne, T. Sultan, F. Rezai, Effects of Selective Laser Melting Additive Manufacturing Parameters of Inconel 718 on Porosity, Microstructure and Mechanical Properties, Materials Science \& Engineering AS0921-5093(18)31093-1,2018

10. Chongliang Zhong, Jochen Kittela, Andres Gassera, Johannes Henrich Schleifenbaum, Study of nickel-based super-alloys Inconel 718 and Inconel 625 in highdeposition- rate laser metal deposition, Optics and Laser Technology 109 (2019) 352-360

11. Bonny Onuike, Bryan Heer, Amit Bandyopadhyay, Additive manufacturing of Inconel 718 - Copper alloy bimetallic structure using laser engineered net shaping (LENSTM), Additive Manufacturing 21 (2018) 133-140

12. Mario Valdez Christopher Kozuch, Eric J. Faierson, Iwona Jasiuk, Induced porosity in Super Alloy 718 through the laser additive manufacturing process: Microstructure and mechanical properties, Journal of Alloys and Compounds 725 (2017) $757 \mathrm{e} 764$

13. Yen-Ling Kuo, Shota Horikawa, Koji Kakehi, The effect of interdendritic $\delta$ phase on the mechanical properties of Alloy 718 built up by additive manufacturing, Materials \& Design, doi: 10.1016/j.matdes.2016.12.026.

14. Lin Zhu, Zhoufeng Xu, Yuefeng Gu, Effect of laser power on the microstructure and mechanical properties of heat treated Inconel 718 superalloy by laser solid forming, Journal of Alloys and Compounds (2018), doi: 10.1016/j.jallcom.2018.02.268 


\section{Comprehensive report on Materials for Gas Turbine Engine Components}

15. Xing Li, J.J. Shi, C.H.Wang, G.H. Cao, A.M. Russell, Z.J. Zhou, C.P. Li, G.F. Chen, Effect of heat treatment on microstructure evolution of Inconel 718 alloy fabricated by selective laser melting, Journal of Alloys and Compounds 764 (2018) 639-649.

16. Y. Tiana, A. Gontcharovb, R. Gauvina, P. Lowdenb and M. Brochua, Effect of heat treatments on microstructure evolution and mechanical properties of blended Nickel-based superalloys powders fabricated by laser powder deposition, Materials Science \& Engineering A, http://dx.doi.org/10.1016/j.msea.2016.07.116

17. C. Li, R. White, X.Y. Fang, M. Weaver, Y.B.Guo, Microstructure Evolution Characteristics of Inconel 625 Alloy from Selective Laser Melting to Heat Treatment, Materials Science \& Engineering A, http://dx.doi.org/10.1016/j.msea.2017.08.058

18. R. Konecna, L. Kunz, G. Nicoletto, A. Baca, Fatigue crack growth behavior of Inconel 718 produced by selective laser melting, Frattura Ed Integrita Strutturale, 2016;(35):31.

19. M.Probstle, S.Neumeier, J.Hopfenmuller, L.Freund, T.Niendorf, D.Schwarze, M.Goken, Superior creep strength of a nickel- based superalloy produced by selective laser melting, Mater. Sci. Eng.: A 2016; 674299-307

20. Y.Kuo, S.Horikawa, K.Kakehi, Effects of build direction and heat treatment on creep properties of Ni-base superalloy built up by additive manufacturing, Scr. Mater. 2017; 12974-78

21. G. Strano, L. Hao, R.M. Everson, K.E. Evans, Surface roughness analysis, modelling and prediction in selective laser melting, J. Mater. Process. Technol. 2013;213(4):589-597.

22. I.Gurrappa, I.V.S.Yashwanth, J.S.Burnell-Gray, Sulfidation characteristics of an advanced superalloy and comparison with other superalloys intended for gas turbine use, The Minerals, Metals \& Materials Society and ASM International 2013, DOI: 10.1007/s11661-013-1859-8

23. J.G. Gonzalez-Rodriguez, S. Haro, A. Martinez-Villafa, V.M. Salinas-Bravo, J. Porcayo-Calderon, Corrosion performance of heat resistant alloys in Na2SO4-V2O5 molten salts, Materials Science and Engineering A 435-436 (2006) 258-265

24. T. S. Sidhu, S. Prakash, R. D. Agrawal, Study of Molten Salt Corrosion of High Velocity Oxy-Fuel Sprayed Cermet and Nickel-Based Coatings at $900^{\circ} \mathrm{C}$, DOI: $10.1007 / \mathrm{s} 11661-006-9002-8$ _ The Minerals, Metals \& Materials Society and ASM International 2007

25. D. Saber, Islam S. Emam, R. Abdel-Karim, High temperature cyclic oxidation of $\mathrm{Ni}$ based superalloys at different temperatures in air, Journal of Alloys and Compounds 719 (2017) 133e141

26. Shaolin Li, Xiaoguang Yang, Hongyu Qi, Jianan Song, Duoqi Shi, Low-Temperature Hot Corrosion Effects on the Low-Cycle Fatigue Lifetime and Cracking Behaviors of a Powder Metallurgy Ni-Based Superalloy, International Journal of FatigueS0142-1123(18)30270-6 DOI:https://doi.org/10.1016/j.ijfatigue.2018.06.035

27. G.A. El-Awadia, S. Abdel-Samada, Ezzat S. Elshazly, Hot corrosion behavior of Ni based Inconel 617 and Inconel 738 superalloys, Applied Surface Science 378 (2016) 224-230

28. V. Demetriou, J.D. Robson, M. Preuss, R. Morana, Study of the effect of hydrogen charging on the tensile properties and microstructure of four variant heat treatments of nickel alloy 718 , international journal of hydrogen energy xxx (2017) 1-15

29. Y. Noguchia, H. Okadaa, H. Hirataa, F. Minami, Effect of aging on high temperature fatigue properties of $\mathrm{Ni}-23 \mathrm{Cr}-7 \mathrm{~W}$ alloy for boiler pipes and tubes, International Journal of Pressure Vessels and Piping 165 (2018) 81-89

30. Enxiang Pua, Wenjie Zheng, Zhigang Song, Ke Zhang, Shuang Liu, Wenxing Shen, Han Dong, Evolution of microstructure and tensile properties during solution treatment of nickel-based UNS N10276 alloy, Materials Science \& Engineering A, http://dx.doi.org/10.1016/j.msea.2017.08.101

31. Y.C. Lin, Hui Yang, Ling Li, Effects of solutionizing cooling processing on $\gamma$ " $(\mathrm{Ni3Nb})$ phase and work hardening characteristics of a Ni-Fe-Cr-base superalloy Vacuum (2017), doi: 10.1016/ j.vacuum.2017.07.025.

32. Li-ming TAN, Yi-wen ZHANG, Jian JIA, Shou-bo HAN, Precipitation of $\mu$ Phase in Nickel - based Powder Metallurgy Superalloy FGH 97, Journal of iron and steel research, International, 2016, 23 (8) : 851-856.

\section{AUTHORS PROFILE}

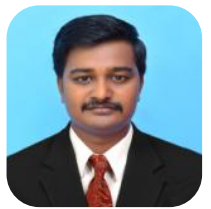

Mr. Anushraj B graduated in 2012 from St.Xavier's Catholic College of Engineering, India. In 2014, he received his M.E Degree in Energy Engineering from Regional Campus of Anna University, Tirunelveli, India. Currently, he is a research scholar at Kalasalingam Academy of Research and Education, India.

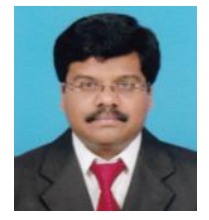

Dr. Winowlin Jappes J T graduated in 1997 from Manonmaniam Sunderanar University, India in Mechanical Engineering. In 1999, he has completed his masters in Production Engineering from Annamalai University. He completed his Ph.D degree in 2004 in the area of Composite Deposition at Indian Institute of Technology Madras, Chennai. He has completed three DST funded research projects and published more than 125 research articles which include 65 International Journal papers. Currently, he is working as Senior Professor in Kalasalingam University, India. His research interest includes high performance composite materials, machining of hard materials, optimization techniques, etc. At present, he is working as Professor and Dean, School of Automotive and Mechanical Engineering, Kalasalingam Academy of Research and Education, India.

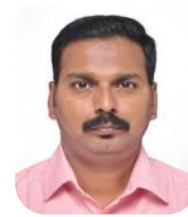

Dr. Adam Khan M is a Post-Doctoral Researcher from the Department of Mechanical and Industrial Engineering Technology, University of Johannesburg, South Africa. He received his Doctoral Degree from National Institute of Technology, Tiruchirappalli, India for his research in Surface Engineering studies on high temperature materials. His Bachelor (B.E.) and Master Degree (M.E.) from Anna University, Chennai in the specialization of Production and Design. Dr. Adam Khan research is focused on surface engineering and metallurgical analysis on processed materials. $\mathrm{He}$ has published 38 technical articles in different journals of international repute.

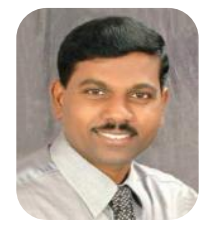

Dr. Dillibabu V received his Doctoral Degree from National Institute of Technology, Tiruchirappalli, India. Currently, he is a scientist at Gas Turbine Research Establishment, DRDO, Bangalore

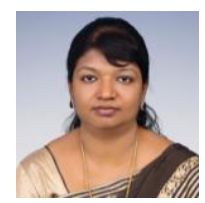

Dr. Brintha N C graduated in 2002 from Manonmaniam Sunderanar University, India. In 2006 she received her M.E Degree with distinction in Computer Science and Engineering from A.K.C.E, Anna University, Chennai. She completed her P.hd degree in 2018 in the area of Cloud Manufacturing under Anna University, Chennai. Currently, she is working as Associate professor/ CSE in Kalasalingam Academy of Research and Education, India. Her research interests include Cloud computing, Optimization, Scheduling, Cloud Manufacturing and so forth. 